\title{
OVER HET ALCOHOLISME OP ARUBA
}

Het alcoholisme is op Aruba geen nieuw medisch probleem, immers reeds omstreeks 1840 constateerde dominee Bosch - een Nederlands Protestants geestelijke die toentertijd het eiland bezocht - dat het alcoholisme onder de Arubanen een ernstig probleem vormde 21 . Niettegenstaande de lange geschiedenis en de urgentie van het probleem ${ }^{4}$, zijn er tot nu toe slechts weinig publicaties aan gewijd; de oudste twee hiervan zijn die van de maatschappelijk werkster Berkley ${ }^{2}$ in 1956 , en van de huisarts Turfboer ${ }^{22}$ een jaar later. Hierna werd er niets meer over gepubliceerd tot 1970, toen op het eiland het eerste Antilliaanse Congres over Alcoholisme werd gehouden.

Wat betreft sociaal-psychiatrische afwijkingen vertoont Aruba enige opmerkelijke verschillen in prevalence-rates vergeleken met Nederland en de overige vijf Nederlands-Antilliaanse eilanden. Opmerkelijk is bv. dat Aruba waarschijnlijk een hogere prevalence-rate heeft voor alcoholisme vergeleken met Nederland ${ }^{11}$ en met Curaçao ${ }^{20}$, een lagere prevalence-rate voor neurotische aandoeningen dan Nederland ${ }^{4}$, en de laagste prevalence-rate voor illegitimiteit (d.w.z. buitenechtelijke geboorten en concubinaat) in de Nederlandse Antillen ${ }^{20}$, hoewel deze laatste significant hoger is dan het Nederlandse cijfer ${ }^{13}$. Illegitimiteit schijnt geen belangrijke rol te spelen in de pathogenese van het alcoholisme op Aruba, aangezien er een duidelijke discrepantie bestaat tussen de diverse bevolkingsgroepen op het eiland en wel in die zin, dat de autochthone Arubaanse bevolking relatief hoge prevalence-rates heeft voor alcoholisme en tevens voor (schijnbaar) patriarchale gezinsstructuur alsmede lage prevalence-rates voor illegitimiteit terwijl de niet-Arubaanse voornamelijk Negroïde bevolkingsgroepen juist lage prevalence-rates hebben voor alcoholisme en tevens hoge voor matriarchale gezinsstructuur en illegitimiteit; het zgn. 'Caraibische gezinstype', zoals dat typisch voorkomt onder de Negrö̈de bevolking van het Caraïbische gebied, heeft dus mogelijk slechts geringe invloed gehad. Beaubrun ${ }^{1}$ is eveneens van mening, dat het 'Caraïbische gezinstype' van geringe invloed is in de pathogenese van alcoholisme in West-Indië. 


\section{OMVANG VAN HET PROBLEEM}

Turfboer 22 vond ongeveer 400 alcoholisten onder de ca. 6.700 werknemers van de olieraffinaderij Lago Oil \& Transport Company in de vijftiger jaren, dwz. ca. $6 \%$ der werknemers. De Lago heeft altijd een negatieve selectie toegepast t.o.v. alcoholisten onder haar werknemers, zodat men mag aannemen dat de prevalence-rate van alcoholisme onder de totale werkende bevolking hoger zal zijn dan $6 \%$. Misschien zou dit cijfer ca. $10 \%$ kunnen bedragen - maar dit is slechts een persoonlijke schatting - van de totale werkende bevolking, die in 1966 ongeveer 17.000 bedroeg $^{20}$. Aldus zou men een aantal van ca. 1.700 alcoholisten kunnen verwachten (1966) op een totale bevolking van ca. 60.000 , dwz. $3 \%$ van de totale bevolking.

Onder de term 'werkende bevolking' wordt verstaan het aantal in een bepaald jaar werkzame en werkzoekende personen van 10 jaar en ouder. Volgens tabel 38c van het Statistisch Jaarboek N.A. 1971 is slechts ca. $1 \%$ van de werkende bevolking van Aruba jonger dan 15 jaar en slechts ca. $2 \%$ ouder dan 60 jaar. Onder het niet-werkende deel van de bevolking jonger dan 15 jaar komen geen alcoholisten voor, aangezien alcoholisme slechts optreedt onder de 'drinking age population' (D.A.P.) d.w.z. de populatie ouder dan 15 jaar. Onder het niet-werkende deel van de bevolking ouder dan 60 jaar komen wel alcoholisten voor, mogelijk $5 \%$ van het totaal aantal alcoholisten (Fig. 1), hetgeen dus het becijferde aantal van 1.700 met nog eens 85 verhoogt tot (afgerond) 1.800 .

In de Verenigde Staten 9 bedraagt de prevalence-rate ongeveer $21 / 2-3 \%$ van de totale bevolking, en in Nederland ${ }^{11}$ ongeveer $0,75 \%$. Misschien liggen de Arubaanse cijfers hoger - en vooral de Politieverslagen hebben ons tot deze opinie verleid - aangezien deze voor bv. 1967 ongeveer 3.200 assistenties wegens alcoholisme vermeldden. Dit cijfer is echter wellicht te hoog, omdat Politieverslagen slechts melding maken van het aantal assistenties en niet van het aantal hierbij betrokken cliënten. Wellicht ligt ook hier de waarheid in het midden, bv. in de buurt van ca. 2.500 alcoholisten (ca. $4 \%$ der totale bevolking).

Enige ziekenhuisgegevens: in 1970 waren er 341 ziekenhuisopnames wegens psychiatrische en/of neurologische aandoeningen in het San Pedro Hospitaal te Oranjestad, waarvan 111 wegens alcoholisme, i.e. $32 \%$ van alle psychiatrisch-neurologische opna- 
mes. Vergelijkbare (dwz. ca. 30\%) opnamecijfers werden gerapporteerd door De Windt ${ }^{25}$, directeur-geneesheer van 's-Lands Psychiatrisch Ziekenhuis 'Rustoord' te Curacao, waar alle chronisch en ernstig krankzinnigen uit de Nederlandse Antillen worden opgenomen voor langdurige observatie en behandeling. Niettemin dient men te bedenken, dat in 'Rustoord' uitsluitend psychiatrische patiënten worden opgenomen, geen neurologische. Indien men dus de neurologische opnames zou extrapoleren, dan zou het percentage alcoholisten onder de psychiatrische opnames in het San Pedro Hospitaal aanzienlijk hoger blijken te zijn dan $32 \%$, hoewel waarschijnlijk niet zo hoog als het percentage voor de Virgin Islands (U.S.) nl. 50\% - mogelijk het hoogste uit het hele Caraïbische gebied ${ }^{14}$.

$$
\text { SEX - RATIO }
$$

Tussen oktober 1969 en april 1971 werden er 100 alcoholisten behandeld in het San Pedro Hospitaal; hiervan waren er 92 mannen en 8 vrouwen - hetgeen in overeenstemming is met gegevens uit de Politieverslagen over $1967^{6}$ en over het eerste halfjaar van $1970^{15}$. Dit levert dus een sex-ratio van $11,5: 1(\mathrm{M}: \mathrm{V})$.

\section{LEEFTIJDSVERDELING}

De gemiddelde leeftijd bij opname bedroeg voor mannelijke patiënten 41 jaar, en voor vrouwelijke patiënten 44 jaar. Uit Fig. 1 (leeftijdsverdeling) blijkt, dat ca. $70 \%$ van de patiënten tussen de 30 en de 50 jaar oud was; $85 \%$ tussen de 25 en de $55 ; 93 \%$ tussen de 20 en de $60 ; 2 \%$ was jonger dan 20 en $5 \%$ ouder dan 60 ; jonger dan 15 of ouder dan 75 was geen der patiënten. De gemiddelde leeftijd bij opname voor beide geslachten bedroeg $41 \frac{1 / 4}{4}$ jaar.

Alcoholisme op Aruba is dus duidelijk een mannenziekte; het begint zich te manifesteren na het 15 e levensjaar en het wordt nog slechts sporadisch aangetroffen boven de leeftijd van 60 jaar. Deze gegevens zijn in overeenstemming met cijfers uit andere landen en verschillen slechts weinig van de gegevens door ons gerapporteerd over de periode oktober 1969 - september $1970^{23}$. Ketel $^{11}$ bv. vond een sex-ratio van $4: 1$ onder Nederlandse alcoholisten. 
Van de mannelijke patiënten waren er 55 gehuwd, 4 leefden er in concubinaat, 4 waren gescheiden, en 29 waren er ongehuwd; dwz. $40 \%$ der mannelijke patiënten was niet gehuwd. Van de vrouwelijke patiënten waren er 4 gehuwd en 4 leefden er in concubinaat. Van alle patiënten (mannen en vrouwen) was $59 \%$ gehuwd, hetgeen iets lager ligt dan het percentage (70\% tussen 15 en 65 jaar) voor de gehele bevolking. Dit verschil is statistisch significant: $X^{2}=5,76 ; \mathrm{df}=1 ; \mathrm{P}<0,025$.

\section{VÓÓRKOMEN IN DE BEVOLKINGSGROEPEN}

Er werd slechts een globale onderverdeling gemaakt in 'Arubanen' en 'niet-Arubanen', vanwege de betrekkelijk geringe getallen waarover wij beschikten.

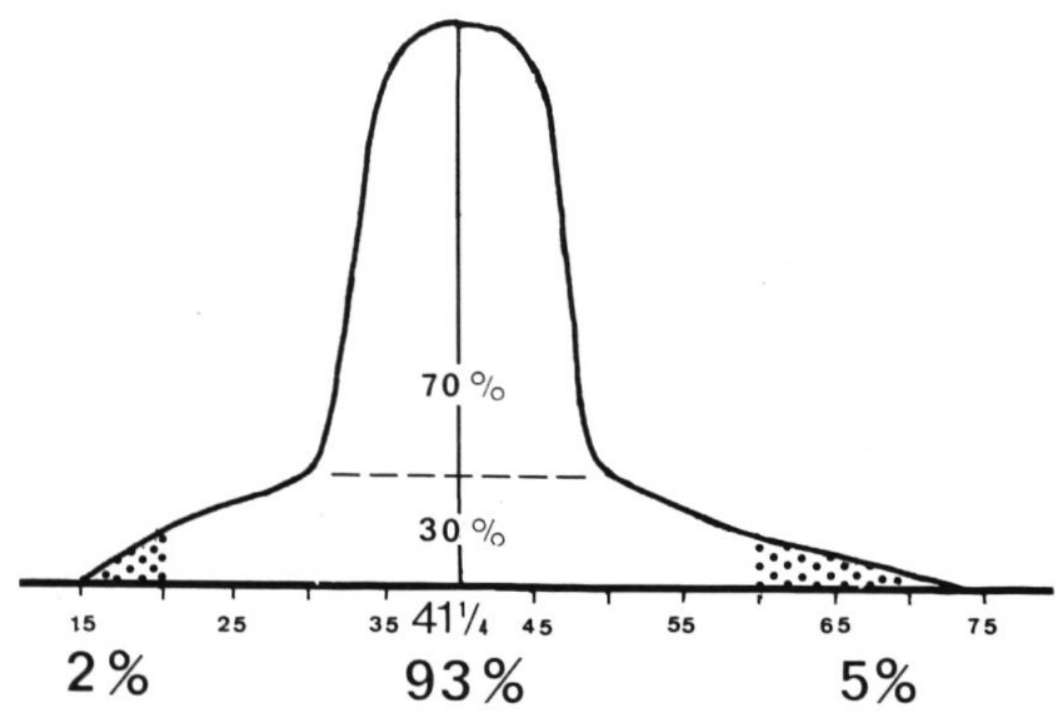

Fig. 1. Leeftïdsverdeling bij 100 opgenomen alcobolisten op Aruba.

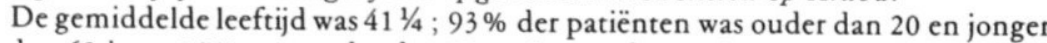
dan 60 jaar; $70 \%$ was ouder dan 30 en jonger dan 50 jaar; $2 \%$ was jonger dan 20 jaar, en $5 \%$ ouder dan 60 jaar. Deze leeftijdsgrenzen zijn nagenoeg congruent met die van de werkende bevolking op Aruba. 
Onder de mannelijke patiënten waren er 73 (80\%) Arubanen en $19(20 \%)$ niet-Arubanen.

Onder de vrouwelijke patiënten waren er $4(50 \%)$ Arubanen en 4 $(50 \%)$ niet-Arubanen.

Onder de totale patiëntenpopulatie bedroeg het aantal Arubanen $77(77 \%)$, niet-Arubanen $23(23 \%)$, welke cijfers enigermate verschillen van de respectievelijke percentages in de gehele bevolking, nl. 65\%-70\% Arubanen en 30\%-35\% niet-Arubanen. Deze cijfers zijn in hun verschil statistisch significant:

$\mathrm{X}^{2}=4,50 ; \mathrm{df}=1 ; \mathrm{P}<0,05$.

Deze cijfers geven aan, dat het voorkomen van 'alcoholismemet-complicaties' (de overgrote meerderheid van onze patiënten) onder Arubanen ongeveer 1,5 à 2 keer zo groot is als onder de niet-Arubanen op het eiland.

Uit politieverslagen uit 1953 en $1954^{2}$ kan men leren, dat toentertijd de frequentie van (door de Politie gerapporteerde) alcoholisten onder de Arubanen ca. 3 à 4 keer zo groot was als onder de niet-Arubanen, aangezien er $80 \%$ assistenties waren voor Arubaanse en $20 \%$ voor niet-Arubaanse alcoholisten, terwijl in die jaren de bevolking globaal bestond uit ca. 50\%-55\% Arubanen en ca. $45-50 \%$ niet-Arubanen. Dit zou er mogelijk op kunnen wijzen, dat tegenwoordig de niet-Arubaanse groeperingen frequenter door deze ziekte worden getroffen dan in het vrij recente verleden.

Een mogelijke verklaring: misschien gaat er van de totale Arubaanse sociale, culturele, psychische en natuurlijke omgeving een positief selecterende werking uit, waarbij in alle bevolkingsgroepen het alcoholisme uit zijn latent fase wordt 'losgewoeld' .

\section{VÓÓRKOMEN IN DE DISTRICTEN}

Door Berkley ${ }^{2}$ en door Janssen 10 is erop gewezen, dat de hoogste frequenties van het alcoholisme op het eiland gevonden worden in de plattelandsdistricten (Nort, Paradera, Santa Cruz, Sabaneta en Brazil). De 2 stadsdistricten (Oranjestad en San Nicolás) omvatten volgens recente gegevens ca. $54 \%$ van de totale bevolking. Niettemin waren $58 \%$ van onze patiënten afkomstig uit de plattelandsdisctricten, en $42 \%$ uit de 2 stadsdistricten. Deze cijfers zijn in hun verschil statistisch significant:

$\mathrm{X}^{2}=5,80 ; \mathrm{df}=1, \mathrm{P}<0,025$.

De relatieve frequentie van vóórkomen van 'alcoholisme-met- 
complicaties' in de plattelandsdistricten is dus ca. 1,5 keer zo groot als in de stadsdistricten (Tab. 1).

TABEL 1

Verdeling der patiënten naar district van herkomst op Aruba

\begin{tabular}{|c|c|c|}
\hline District & Aantal & Percentage \\
\hline $\begin{array}{l}\text { Paradera } \\
\text { Nort } \\
\text { Santa Cruz } \\
\text { Sabaneta \& Brazil }\end{array}$ & $\begin{array}{r}17 \\
16 \\
16 \\
9\end{array}$ & $\left.\begin{array}{r}17 \% \\
16 \% \\
16 \% \\
9 \%\end{array}\right]-58 \%$ \\
\hline $\begin{array}{l}\text { San Nicolás } \\
\text { Oranjestad }\end{array}$ & $\begin{array}{l}20 \\
22\end{array}$ & $\left.\begin{array}{l}20 \% \\
22 \%\end{array}\right] 42 \%$ \\
\hline
\end{tabular}

\section{FAMILIAIR VÓÓRKOMEN}

Het familiair voorkomen werd geëvalueerd aan de hand van 33 stambomen van alcoholisten, waaruit de volgende mogelijke corrélaties naar voren'kwamen:

1) $27(82 \%)$ hadden een vader, die alcoholist was.

2) $20(60 \%)$ hadden 1 of meer broers, die alcoholist waren.

3) $9(27 \%)$ hadden 1 of meer ooms van vaderskant, die alcoholist waren.

4) 0 hadden alcoholisten onder hun moeders, zusters, dochters, tantes van vaderskant of moederskant, of grootmoeders.

De overige correlaties waren niet indrukwekkend.

Volgens Fox ${ }^{8}$ komt het in de Verenigde Staten bij $52 \%$ van de alcoholisten voor, dat één of beide ouders ook alcoholist zijn hetgeen evident lager ligt dan in onze serie. Niettemin, hoe suggestief deze cijfers ook mogen zijn voor de theorie der genetische pathogenese, toch sluiten zij de mogelijkheid van een 'culturele overerving' niet bij voorbaat uit.

\section{SOCIOPATHOLOGISCHE ASPECTEN}

Vele onderzoekers stellen, dat het alcoholisme zich vooral ontwikkelt op de bodem van sociale problemen, en dat de prognose voornamelijk afhangt van sociale factoren. In een poging, deze sociale factoren te verkennen, werden er 33 milieurapporten ge- 
maakt door de maatschappelijk werker M. Boekhoudt (Tab. 2). De belangrijkste bevindingen waren de volgende:

1) De Arubaanse alcoholist heeft vaak $(60 \%)$ een afhankelijke attitude t.o.v. zijn moeder, en soms ook t.o.v. zijn vrouw (40\%).

2) Hij vertoont vaak een afhankelijke maar conflict-beladen attitude t.o.v. zijn vrouw (40\%), maar slechts sporadisch t.o.v. zijn moeder (9\%).

Soms is hij vijandig t.o.v. zijn vrouw (13\%), maar slechts sporadisch t.o.v. zijn moeder.

3) Een normale attitude t.o.v. moeder of echtgenote hadden slechts $6 \%-7 \%$.

4) Slechts $23 \%$ (6 van de 26) hadden een harmonieuze huiselijke omgeving in hun jeugd gekend; $77 \%$ hadden moeilijkheden gehad in hun thuismilieu in hun jeugdjaren, variërend van 'apathisch milieu' tot 'bedekte' of zelfs 'openlijke conflicten'.

5) $42 \%$ hadden een vader met een 'empty father's image', dwz. een vader van zeer laag allooi of met een minimum aan identificatiemogelijkheden.

$13 \%$ hadden een vader met een 'unreachable father's image', $\mathrm{dwz}$. een vader van uitzonderlijke allure, dusdanig begaafd dat zijn voorbeeld ondanks een overdaad aan identificatiemogelijkheden onhaalbaar en dus onnastrevenswaardig wordt. Gebrek aan identificatiemogelijkheden (in positieve of in negatieve richting) kwam er dus voor in ca. $55 \%$.

Blijkens deze gegevens is onder de Arubaanse alcoholisten een 'empty father's image' dus mogelijk een belangrijker conditionerende factor dan een 'unreachable father's image'. Analoge bevindingen vermeldt Van der Does de Willebois 5 .

6) $73 \%$ (24 van de 33 ) hadden een dominerende, overmatig beschermende, verwennende moeder. Maternele deprivatie kwam slechts sporadisch voor (3\%), evenals de categorie 'aanvaardbare moeders' (6\%).

7) De meesten van onze patiënten hadden slechts weinig opleiding genoten, dwz. veelal niet meer dan lagere school, en zelfs deze voltooiden zij niet of met veel moeite; waarschijnlijk ligt het niveau van de 'verworven intelligentie' van vele Arubaanse alcoholisten dan ook beneden het gemiddelde van de totale bevolking.

8) Meerdan $90 \%$ (63 van de 68) behoorden tot de lagere sociale klassen. 
TABEL 2

Subjectieve perceptic van het voorbeeld van hun vaders door 33 alcoholisten van Aruba

empty father's image'

'unreachable father's image'

onbekende vader

aanvaardbaar voorbeeld

\section{BEHANDELING}

De behandeling, die wij sinds oktober 1969 geven, is er op gericht, de alcoholisten een uitgangspunt te bieden bij het betreden van de lange en moeizame weg naar algehele onthouding en nuchterheid. Tabel 3 stelt schematisch onze behandelingsmethoden en behandelingsresultaten tussen oktober 1969 en april 1971 voor. De volgende feiten zijn vermeldenswaardig:

A. Behandeling werd geweigerd in 28 gevallen.

B. Behandeling was gecontra-indiceerd in 14 patiënten met complicaties van ernstige aard (cardiaal, respiratoir, hepatisch etc.)

C. 10 patiënten werden uitsluitend met groeps-psychotherapie behandeld (niet-analytisch, wel verklarend, ondersteunend en psychagogisch, 'family-centered' dwz. echtgenoten en kinderen participeerden ook.)

D. Een gecombineerde behandeling met Apomorphine en/of Emetine waarna proefdronk ( 4 à 6 keer), èn tevens groepspsychotherapie, werd gegeven aan 22 patiënten.

E. 26 patiënten werden behandeld met Disulfiram zonder proefdronk, of Disulfiram met proefdronk, of Disulfiram plus apomorphine met proefdronk - en tezamen vormden deze 26 patiënten de categorie 'Behandelingsmethoden vóór oktober 1970' (E).

Vóór oktober 1970 gaven wij Disulfiram (Refusal, Antabus) met proefdronk al dan niet voorafgegaan door Apomorphineinjecties, doch wij zijn hiervan afgestapt vanwege de zeer ernstige bijwerkingen hiervan (shock, coma, cyanose etc.), alhoewel deze zich slechts in een drietal patiënten voordeden.

Toch krijgen alle patiënten, mits er geen contra-indicaties zijn, Disulfiram als onderhoudstherapie mee na ontslag uit het ziekenhuis. 
TABEL 3

Behandelingsresultaten van 100 alcoholisten op Aruba per 1 april 1971, in absolute getallen en in percentages

In de verticale kolommen zijn weergegeven: de behandelingscategorieën $\mathrm{A} t / \mathrm{m} \mathrm{E}$, het totaal aantal patiënten in $\mathrm{A} \mathrm{t} / \mathrm{m} \mathrm{E}$, en deze aantallen weer in percentages uitgedrukt. (De percentages tussen twee vette horizontale lijnen vormen steeds $100 \%$.)

In de horizontale kolommen zijn weergegeven: de behandelingsresultaten van die patiënten die zich bij de AA voegden (bovenste drie), de resultaten van die patiënten die zich niet bij de AA voegden (middelste vijf), en de resultaten bij alle 100 patiënten, zowel AA-leden als niet-AA-leden (onderste vijf).

\begin{tabular}{|c|c|c|c|c|c|c|c|}
\hline $\begin{array}{l}\text { Behandelings- } \\
\text { resultaten }\end{array}$ & $\begin{array}{l}\stackrel{A}{\text { Behandeling }} \\
\text { geweigerd }\end{array}$ & $\begin{array}{c}B \\
\text { Contra- } \\
\text { indicaties }\end{array}$ & $\begin{array}{c}\text { C } \\
\text { Groeps- } \\
\text { s therapie }\end{array}$ & $\begin{array}{c}D \\
\text { Aversiekuur } \\
\text { (apomorphine } \\
\text { of emetine) \& } \\
\text { Groepstherapie }\end{array}$ & $\begin{array}{l}\quad \quad E \\
\text { Behandelings- } \\
\text { methoden } \\
\text { vóór oktober } \\
1970\end{array}$ & Totaal & $\begin{array}{l}\text { Per- } \\
\text { cen } \\
\text { tage }\end{array}$ \\
\hline $\begin{array}{l}\text { AA } \\
\text { nuchter }\end{array}$ & $6(67 \%)$ & $4(100 \%)$ & $4(50 \%)$ & $11(73 \%)$ & $8(44 \%)$ & 33 & $60 \%$ \\
\hline $\begin{array}{l}\text { AA } \\
\text { 'semi nuchter' }\end{array}$ & $2(22 \%)$ & - & $1(13 \%)$ & $1(7 \%)$ & $6(33 \%)$ & 10 & $19 \%$ \\
\hline $\begin{array}{l}\text { AA } \\
\text { niet nuchter }\end{array}$ & $1(11 \%)$ & - & $3(37 \%)$ & $3(20 \%)$ & $4(23 \%)$ & 11 & $21 \%$ \\
\hline nuchter & $4(21 \%)$ & - & $1(50 \%)$ & $1(16 \%)$ & $2(25 \%)$ & 8 & $17 \%$ \\
\hline 'semi-nuchter' & $2(11 \%)$ & - & - & $1(28 \%)$ & $2(25 \%)$ & 6 & $13 \%$ \\
\hline niet nuchter & $4(21 \%)$ & $4(40 \%)$ & $1(50 \%)$ & $2(28 \%)$ & $2(25 \%)$ & 13 & $28 \%$ \\
\hline 'Lost to follow-up' & $8(42 \%)$ & $4(40 \%)$ & - & $2(28 \%)$ & $1\left(12 \frac{1}{2} \%\right)$ & 15 & $33 \%$ \\
\hline overleden & $1(5 \%)$ & $2(20 \%)$ & - & - & $1\left(12 \frac{1}{2} \%\right)$ & 4 & $9 \%$ \\
\hline totaal nuchter & $10(36 \%)$ & $4(281 / 2 \%)$ & $5(50 \%)$ & $12(55 \%)$ & $10(38 \%)$ & 41 & $41 \%$ \\
\hline totaal 'semi-nuchter' & $4(14 \%)$ & - & $1(10 \%)$ & $3(14 \%)$ & $8(31 \%)$ & 16 & $16 \%$ \\
\hline totaal niet nuchter & $5(18 \%)$ & $4(281 / 2 \%)$ & $4(40 \%)$ & $5(23 \%)$ & $6(23 \%)$ & 24 & $24 \%$ \\
\hline $\begin{array}{l}\text { totaal } \\
\text { 'Lost to follow-up' }\end{array}$ & $8(28 \%)$ & $4(281 / 2 \%)$ & - & $2(8 \%)$ & $1(4 \%)$ & 15 & $15 \%$ \\
\hline totaal overleden & $1(4 \%)$ & $2\left(14 \frac{1}{2} \%\right)$ & - & - & $1(4 \%)$ & 4 & $4 \%$ \\
\hline $\begin{array}{l}\text { totaal } \\
\text { aantal patiënten }\end{array}$ & 28 & 14 & 10 & 22 & 26 & 100 & $100 \%$ \\
\hline
\end{tabular}


Er werd ook een onderverdeling gemaakt in patiënten die wel of geen AA-leden werden, en in patiënten die nuchter waren, 'semi-nuchter' (dwz. meestal nuchter met slechts af en toe een 'slip'), niet nuchter, 'lost to follow-up', of overleden per 1 april 1971.

\section{RESULTATEN}

De resultaten zijn te vinden in Tabel 3.

Van onze 100 patiënten waren er per 1 april 197141 volledig nuchter, 16 'semi-nuchter', 15 'lost to follow-up', 24 niet-nuchter, en 4 overleden. Van de overledenen stierven er 2 aan levercirrhose, 1 stierf de verdrinkingsdood wàarschijnlijk tijdens een alcoholconvulsie, en 1 stierf tengevolge van een ernstige methanol intoxicatie met zgn. 'Bay-rum', een lokaal praeparaat dat gebruikt wordt als opfrissertje doch door chronische alcoholisten ook gedronken wordt vanwege de voordelige prijs ervan.

De groepen $A$ plus $B$ gecombineerd vertonen een percentage van $42 \%$ nuchtere of 'semi-nuchtere' patiënten (I in Fig. 2).

Groep $C$ vertoont een succespercentage van $60 \%$ (II in Fig. 2.).

Groep $D$ vertoont een succespercentage van $67 \%$ (Cf. III in fig. 2).

Groep $E$ vertoont een succespercentage van $68 \%$ (Cf. IV in fig. 2).

Toch dient er de nadruk op gelegd te worden, dat deze zelfde groep E per september 1970 slechts een succespercentage haalde van $30 \%$; de reden waarom het succespercentage in deze categorie zo sterk lijkt te zijn toegenomen, is te vinden in de omstandigheid, dat vele patiënten uit deze categorie er niet in zijn geslaagd nuchter te blijven ná september 1970, weer opgenomen werden en toen volgens $C$ of $D$ behandeld werden; aldus verlieten zij groep E en lieten die achter met een schijnbaar hoger succespercentage.

Ook dient er op gewezen te worden, dat ons behandelingsdoel vóór september 1970 algehele onthouding was - een typisch vereiste van de Alcoholics Anonymous (Anonieme Alcoholisten, AA) - welk doel op zichzelf mogelijk een reducerende factor kan zijn geweest t.a.v. onze behandelingsresultaten per september 1970 . Volgens Santamaria ${ }^{19}$ kan deze doelstelling zelfs een formidabele barrière vormen in de behandeling van vele alcoholisten, en zelfs zou deze doelstelling recidivisme kunnen provoceren. 
Fig. 2. Behandelingsresultaten van 100 alcoholisten op Aruba.

Grafische voorstelling van de gegevens uit Tabel 3.

De onderste (gebroken) lijn stelt de resultaten van uitsluitend medische behandelingswijzen voor $(30 \%)$. De bovenste (punt-streep) lijn stelt de resultaten voor van medische behandelingswijzen gecombineerd met AA-behandeling $(79 \%)$. De middelste (gesloten) lijn stelt het 'over-all'-succespercentage van de behandelingswijzen voor, en is dus het gemiddelde van de bovenste en onderste lijn $(57 \%)$

Categorie I ( = A + B) stelt die groep patiënten voor, welke behandeling geweigerd hebben (A) èn die, welke geen aversiekuur ondergingen omdat apomorphine, emetine of disulfiram bij hun gecontraïndiceerd was (B).

Categorie II ( = C) stelt die groep patiënten voor, welke uitsluitend behandeld werd met groepstherapie en disulfiram-onderhoudstherapie na ontslag. Categorie III ( = D) stelt die groep patiënten voor, welke behandeld werd met groepstherapie, apomorphine- of emetinekuren, en disulfiram-onderhoudstherapie na ontslag. Categorie IV ( = E) stelt die groep patiënten voor, welke tussen oktober 1969 en oktober 1970 behandeld werd volgens de toendertijd gehanteerde methoden, d.w.z. ofwel aversiekuren met disulfiram en/of apomorphine gevolgd door poliklinische disulfiram-onderhoudstherapie na ontslag. Categorie V stelt het totaal aantal patiënten voor, d.w.z. alle vijf groepen A t/m E tezamen.

Lettend op de middelste lijn kan vastgesteld worden, dat toevoeging van groepstherapie (II en III) en aversiekuren (III) aan de behandeling, tot betere resultaten heeft gevoerd. Lettend op de bovenste lijn kan men vaststellen, dat AA-behandeling gecombineerd met medische behandeling tot betere resultaten heeft gevoerd dan medische behandeling alléén.

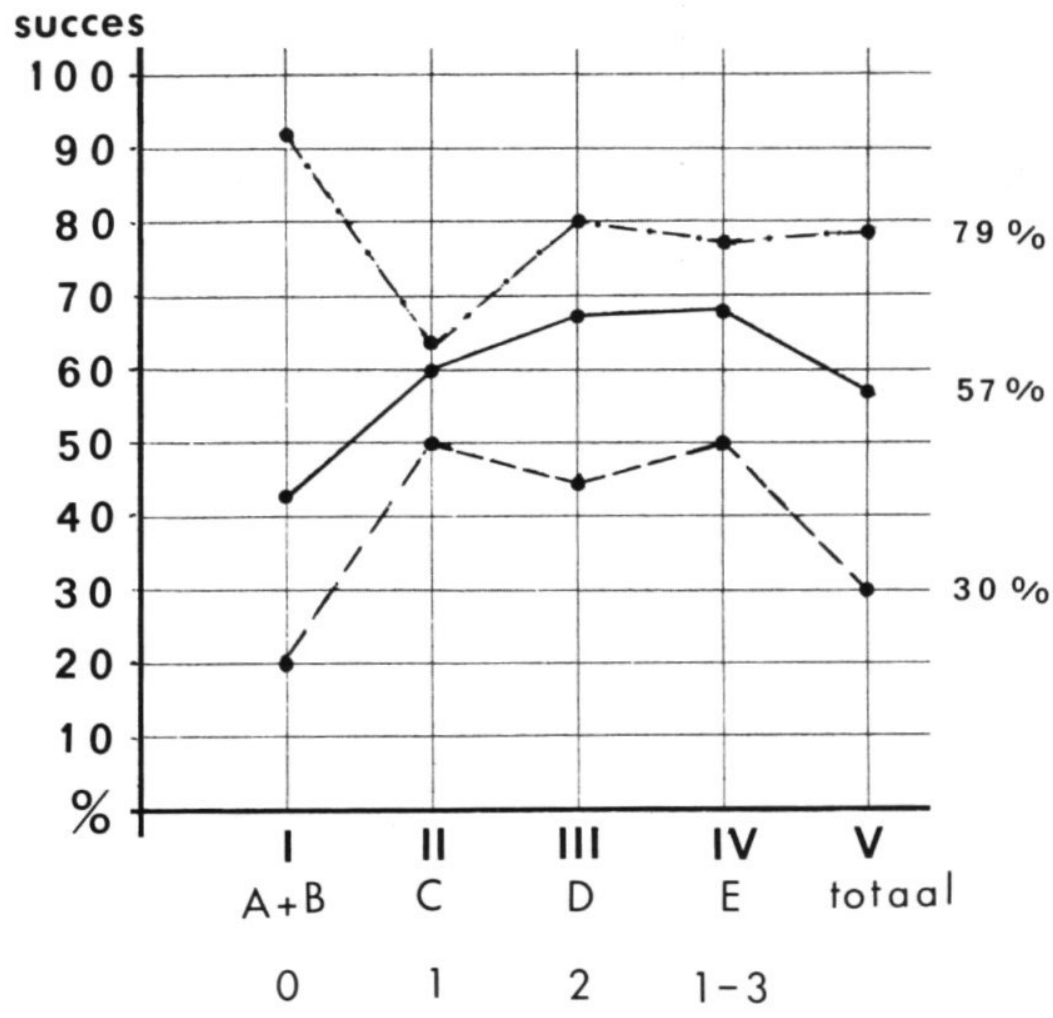


Wij hebben getracht, deze doelstelling te vervangen door een minder hoog opgeschroefd doel, dwz. door ook 'semi-nuchterheid' als aanvaardbare rehabilitatie te accepteren. Mogelijk verklaart dit ook gedeeltelijk onze betere resultaten per 1 april 1971, hoewel ongetwijfeld ook de invoering van groeps-therapie hierop van invloed zal zijn geweest.

Bij een beschouwing van Figuur 2 hebben wij ons ertoe laten verleiden, de toenemende succespercentages in de diverse behandelingscategorieën te correleren met het toenemende aantal behandelingsmethoden in die categorieën (IV $\geqslant$ III > II > I).

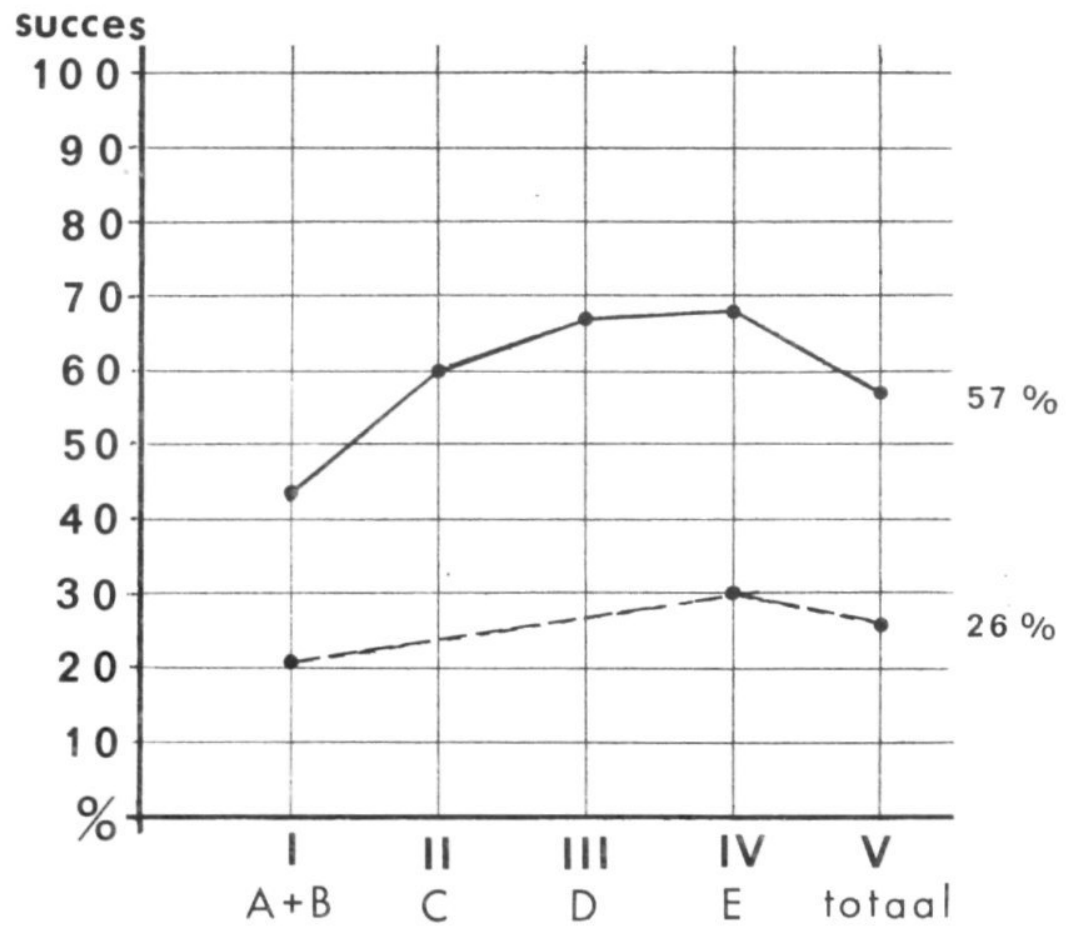

Fig. 3. Behandelingsresultaten van 100 alcoholisten op Aruba.

Vergelijking tussen de resultaten per 1 april 1971 (57\%, gemiddeld ca. 9 maanden na ontslag) en die per 1 september 1970 (26\%, gemiddeld ca. 5 maanden ná ontslag van de patiënt).

De onderste (gebroken) lijn laat zien, dat tussen oktober 1969 en september 1970 slechts de behandelingscategorieën $I(=A+B)$ en IV $(=E)$ van toepassing waren.

Deze onderste lijn ligt duidelijk op een lager niveau dan de bovenste (gesloten) lijn, welke de behandelingsresultaten visualiseert in de behandelingscategorieen, van toepassing tussen 1 oktober 1969 en 1 april 1971. 
Men kan ook de evident betere resultaten waarnemen van diegenen, die zich bij de AA voegden (Fig. 2 en Fig. 3). Figuur 3 visualiseert tevens de betere resultaten over de gehele linie per 1 april 1971.

Rankin 18 vermeldt, dat in een survey onder 11.355 AA-leden in de Verenigde Staten er $60 \%$ nuchter bleken te zijn gedurende 1 jaar, $35 \%$ gedurende 1 à 5 jaar, en $25 \%$ gedurende meer dan 5 jaar. Ook vermeldt hij, dat alle gangbare behandelingsmethoden een vergelijkbaar succespercentage van ca. $30 \%$ opleveren. Poleo Conde ${ }^{16}$ vermeldde vergelijkbare resultaten uit het Hospital Vargas, verbonden aan de Centrale Universiteit van Venezuela te Caracas.

Uit Figuur 2 kan men aflezen, dat uitsluitend AA-behandeling een zeer hoog succespercentage schijnt te hebben, nl. 92\%, terwijl medische behandeling alléén niet verder schijnt te komen dan $30 \%$. Wij hebben dit vergeleken met de resultaten uit éen lokale AA-groep; deze groep bestond uit 40 leden, van wie er 18 nuchter waren per 1 april 1971, dwz. een succespercentage van $45 \%$. Het lijkt er dus op, dat een combinatie van hospitalisatie (zelfs zonder 'klassieke' behandeling) èn $A A$ mogelijk betere resultaten oplevert dan ieder afzonderlijk, althans in de typische AA - dwz. Gamma-alcoholisten. Voor dit hoge succespercentage $(92 \%)$ onder patiënten die uitsluitend AA-behandeling kregen, kan tevens nog als mogelijke verklaring worden aangevoerd, dat zij misschien juist doordat bij hen medische behandeling niet geïndiceerd was of door hen geweigerd werd, beter gemotiveerd waren tot het aanvaarden van het AA-programma.

Tussen 1966 en 1969 werden er in het San Pedro Hospitaal 291 alcoholisten behandeld, met een succespercentage van ca. $25 \%$, dwz. 73 succesvolle gerehabiliteerde patiënten. De behandeling bestond voornamelijk uit ontnuchtering, correctie van complicaties, en Disulfiram zonder proefdronk als onderhoudstherapie. Het huidige succespercentage van $57 \%$ blijkt statistisch significant te verschillen van de behandelingsresultaten tussen 1966 en 1969: $\mathrm{X}^{2}=35,16 ; \mathrm{df}=1 ; \mathrm{P}<0,005$.

Ook de verschillen in succespercentages tussen de behandelingscategorieën ( $\mathrm{A}$ en $\mathrm{B}$ ) enerzijds en $\mathrm{D}$ anderzijds bleken statistisch significant; $\mathrm{X}^{2}=4,25 ; \mathrm{df}=1 ; \mathrm{P}<0,05$. De verschillen tussen ( $A$ en $B$ ) enerzijds en $C$ anderzijds, en die tussen $C$ en $D$ onderling bleken niet significant te zijn.

Het verschil in succespercentage tussen die patiënten, die zich 
wel aansloten bij de AA, en die patiënten, die dat niet deden, bleek wel statistisch significant: $\mathrm{X}^{2}=<23,51$; $\mathrm{df}=1$; $P<0,005$. Het verschil in succespercentage tussen díe patiënten, die niet behandeld werden ( $A$ en $B$ ) en díe patiënten, die wèl behandeld werden $(C, D$, en $E)$ bleek eveneens statistisch significant: $\mathrm{X}^{2}=5,20 ; \mathrm{df}=1 ; \mathrm{P}<0,025$.

Als mogelijke verklaring voor de betere behandelingsresultaten in de periode oktober 1969-april 1971 vergeleken met de periode 1966-1969, kunnen de volgende factoren aangewezen worden:

a) De invoering van groepstherapie.

b) De (her-)invoering van aversiekuren, welke voór 1966 nog toegepast werden doch tussen 1966 en 1969 werden vervangen door een behandelingschema waarin de patiënten de gelegenheid kregen tot 'opdrogen' ('sobering up'), en bij ontslag Disulfiram, multivitamines en sedativa als onderhoudstherapie kregen, tezamen met nazorg door de AA.

c) De intensifiëring van de AA-bezigheden t.a.v. deze patiënten in het ziekenhuis, met name in de zin van AA-participatie in de 2 keer per week plaatsvindende groepstherapeutische zittingen en ook in de vorm van een intensiever en frequenter bezoek aan de opgenomen alcoholisten.

d) Het gebruik van de autochtone taal, d.w.z. het Papiamento, in zowel medische als paramedische contacten met deze patiënten; in de periode vóór oktober 1969 werd deze communicatie tussen medicus en alcoholist belemmerd doordat de voertaal tussen beiden òfwel goed Nederlands òfwel gebrekkig Papiamento was.

\section{AETIOLOGIE}

Uit het voorafgaande moet het duidelijk geworden zijn, dat op Aruba het alcoholisme een groot sociaalmedisch probleem was en nog steeds is, vooral onder de autochtone Arubaanse (plattelands) bevolking, die op te vatten is als een trihybridisch volk met overwegend Indiaanse en Caucasoïde doch ook met Negroïde kenmerken. Het is nog steeds een vrij vaak voorkomende opinie, dat het alcoholisme onder de Arubanen een groot probleem is ,,vanwege hun Indiaans bloed" 3 . Nog steeds is het niet uitgemaakt of het alcoholisme onder de Arubaanse bevolking genetisch dan wel cultureel overgedragen wordt of op beide wijzen. Evenmin is er vastgesteld, of er belangrijke psychologische factoren in de pathogenese van het Arubaanse alcoholisme betrokken zijn.

Wel dient er op gewezen te worden, dat er op het eiland in het 
algemeen in de beginfase van de ziekte een positieve attitude bestaat t.o.v. drinken en zelfs dronkenschap, in díe zin dat dit beschouwd wordt als (status)symbool van 'echte mannelijkheid'. Ook het feit dat tegenwoordig de niet-Arubaanse bevolkingsgroepen vaker dan voorheen door deze ziekte getroffen worden, kan mogelijk wijzen in de richting van socio-culturele factoren, bv. in de zin van culturele adaptatie, 'acculturatie' aan de autochtone attitude t.o.v. alcohol. Aan de andere kant schijnt het typisch familiaire vóórkomen in onze patiëntenreeks de mogelijke relevantie van generische overdracht te benadrukken.

\section{PLANNEN VOOR DE TOEKOMST}

1) Een Rehabilitatiecentrum voor chronische alcoholisten, teneinde langdurige sociale readaptatiemogelijkheden te bieden aan alcoholisten met ernstige sociopathologie.

2) 6 Districtshuizen, 1 in ieder district, welke zullen fungeren als vergaderruimten voor de AA-groepen en tevens als spreekkamers voor de sociale werk(st)ers die speciaal aangesteld zullen worden om de alcoholisten in het rehabilitatiecentrum en de districtshuizen sociaal te begeleiden. - Zowel het rehabilitatiecentrum als de 6 districtshuizen zijn projecten van de 'Stichting Bestrijding Alcoholmisbruik Aruba' en zullen gebouwd worden met financiële steun van de Nederlandse, Antilliaanse en Arubaanse overheidsinstanties.

3) Invoering van nieuwere behandelingsmethoden, bv. sociodrama en psychodrama, gezins-psychotherapie, e.a.; Disulfiram-implantatie (Esperal-tabletten) zal spoedig toegepast worden, mits geïndiceerd7. De eerste resultaten met Esperal hopen wij binnenkort te kunnen publiceren.

\section{SAMENVATTING}

Hoewel het alcoholisme op Aruba reeds lang bestaat en een urgent probleem vormt, zijn er tot nu toe slechts weinig studies aan gewijd. Het voorkomen van deze ziekte ligt met ca. $3 \%$ à $4 \%$ van de totale bevolking hoger dan het Nederlandse cijfer (ca. $0,75 \%) .32 \%$ van alle neurologisch-psychiatrische opnames in 1970 betroffen alcoholisme of complicaties daarvan.

Van 100 opgenomen alcoholisten was de sex-ratio 11,5: 1. (M : V), terwijl de gemiddelde leeftijd bij opname $41 \frac{1 / 4}{4}$ jaar bedroeg. $59 \%$ der patiënten was ge. huwd, hetgeen iets lager ligt dan het bevolkingsgemiddelde van $70 \%$ boven de leeftijd van 15 jaar. 
De prevalence van 'alcoholisme-met-complicaties' is mogelijk $1 \frac{1 / 2}{2}$ à 2 keer zo hoog onder de autochtone Arubaanse bevolking als onder de heterochtone groeperingen; er zijn echter aanwijzingen, dat tussen 1953 en 1971 de prevalence onder de heterochtone groeperingen is toegenomen, hetgeen wellicht verklaard zou kunnen worden door 'acculturatie' aan de autochtone drinkgewoonten.

De prevalence ligt hoger in de plattelandsdistricten dan in de stadsdistricten. Van de 33 ondervraagde alcoholisten, bleken 27 een vader te hebben, die ook alcoholist was, terwijl 20 één of meer broers hadden, die ook alcoholist waren; toch sluiten deze gegevens niet bij voorbaat een 'culturele overerving' uit.

Van de 33 ondervraagde patiënten hadden 18 een vader met een 'empty father's image' of 'unreachable father's image' en 24 een moeder met een dominerend, overbeschermend, verwennend karakter. Van de 100, tussen 1 oktober 1969 en 1 april 1971 opgenomen alcoholisten waren er per 1 april 197141 volledig nuchter, en 16 'semi-nuchter'; 24 waren er niet nuchter, 4 overleden en 15 'lost to follow-up'.

De behandeling werd in $57 \%$ als effectief gewaardeerd, terwijl in 14 patiënten behandeling gecontraindiceerd was en in 28 gevallen behandeling geweigerd werd.

De gehanteerde therapie bestond uit: aversiekuur met Disulfiram en/of Apomorphine en/of Emetine, groeps-psychotherapie, Disulfiram als onderhoudstherapie, en 'follow-up' door de Alcoholics Anonymous (AA).

\section{SUMMARY}

Though alcoholism in Aruba constitutes a long-standing and urgent problem, there have been made but few studies on the subject.

The prevalence amounts to $3 \%-4 \%$ of the population, which is higher than the rate for the Netherlands $(0.75 \%)$.

Of all neurological and psychiatric admissions in $197032 \%$ concerned alcoholism and alcoholismic complications.

Among 100 admitted patients the sex-ratio was $11.5: 1$. (M:F), while the average age at admission was $411 / 4$ years.

Of these patients $59 \%$ were married, whicht is just a little bit lower than the rate for the population at large above 15 years, namely $70 \%$. The prevalence of 'alcoholism-with-complications' is possibly $1 \frac{112-2}{2}$ times higher among the autochthonous Aruban population as compared to the heterochthonous population groups; there are indications though that between 1953 and 1971 the prevalence among the heterochthonous groups may have increased, which fact might possibly be explained by 'acculturation' towards the autochthonous drinking habits.

The prevalence appears to be higher in the rural districts than in the urbanized districts.

Of 33 interrogated patients 27 appeared to have an alcoholic father and 20 had also 1 or more alcoholic brothers; nevertheless these facts do not exclude the possiblity of 'cultural inheritance'. 18 out of 33 patients had a father with an 'empty' or 'unreachable father's image', and 24 had a dominating, overprotective, spoiling mother.

Of 100 alcoholic patients admitted from October 1, 1969, to April 1, 1971, 41 were completely sober by April, 1971 , and 16 were 'semi-sober'; 24 were not sober, 4 had died, and 15 were lost to follow-up. Treatment was appreciated as 
effective in $57 \%$, while in 14 patients it was contra-indicated and in 28 cases it was refused. Treatment consisted of: aversive cures with Disulfiram and/or Apomorphine and/or Emetine, group therapy, Disulfiram as maintenance therapy, and follow-up by Alcoholics Anonymous (AA).

Aruba, juni 1971

\section{REFERENCES}

1 Beaubrun, M. H., 1971. Sociocultural factors affecting the incidence and treatment of alcoholism in the Caribbean. Proceedings of the First Aruban and Antilliean Congress on Alcoholism, Aruba, p. 122-134.

2 Berkley, L., 1956. Het alcoholprobleem op Aruba. Scriptie Sociale Academie Eindhoven.

3 Bijl, O. A., 1971. Message from the Public Health Department. Proc. First Aruban Congr. Alcoholism, p. 14-15.

4 Constructive mental hygiene in the Caribbean, 1957. Van Gorcum, Assen, xiv + 176 pp.

5 Does de Willebois, A. E. M. van der, 1965. Vervreemding en verslaving. Dekker \& van de Vegt, Utrecht, viii + 229 pp.

6 Drankmisbruik op Aruba; oorzaak van veel leed. Amigoe di Aruba, 25.IV.1968.

7 Erp, Th. van, 1971. Possibilities of the implant of Disulfiram (Esperal). 17th Intern. Inst. on the prevention and treatment of Alcoholism, West-Berlin (not publ.).

8 Fox, Ruth, 1968. A multidisciplinary approach to the treatment of alcoholism. Int. J. Psychiatry 5, p. 34-44.

9 Gant, J. C., 1968. Treatment of the alcohol withdrawal syndrome. J. Tennessee Med. Ass. 61, p. 45-47.

10 Janssen, J. H. G., 1971. Some general aspects of alcoholism in Aruba. Proc. First Aruban Congr. Alcoholism, p. 18-28.

11 Ketel, A. P., 1963. Gegevens betreffende alcoholzucht en ambulante behandeling van alcoholisten. Ned. Tijdschr. Geneesk. 107, 16 apr., p. 641648.

12 Marie, Claude, 1955. A propos du nouveau mode de traitement de l'alcoolisme chronique par implantation de disulfure de tétra-éthyle-thio-urame. Thesis, Paris.

13 Mertens, A. Th. L. M., et al., 1965. De patiënt als gezinslid. Dekker \& van de Vegt, Nijmegen, viii + 259 pp.

14 Murphy, H. B. \& Sampath, H. M., 1969. The hospitalized patient. In Workshop on Alcoholism, U.S. Virgin Islands, 128 pp. (not publ.), p. 1-11.

15 Oldenboom, J. F., 1971. Criminological and policial aspects of alcoholism in Aruba. Proc. First Aruban Congr. Alcoholism, p. 96-99.

16 Poleo Conde, M., 1971. Aspectos del tratamiento del alcoholismo en Venezuela. Proc. First Aruban Congr. Alcoholism, p. 56-69.

17 Prigent, M. L., 1960. Place de l'application du disulfure de tétra-éthylethio-urame dans le traitement de l'alcoolisme chronique. Thesis, Rennes. 
18 Rankin, J. G., 1969. Definitive treatment of alcoholism. In Symposium Alcoholism-problems in treatment, Univ. Melbourne, 78 pp. (p. 31-39).

19 Santamaria, J. N., 1969. Treatment of the 'incurable' alcoholic patient. In Symp. Alcoholism-problems in treatment, Melbourne, 78 pp. (p. 44-49).

20 Statistisch Jaarboek Nederlandse Antillen, 1971.

21 Steenmeyer, F., 1957. Food and nutrition of Arubans. Thesis, Utrecht, viii +139 pp.

22 Turfboer, R., 1957. The effects of in-plant rehabilitation of alcoholics. Med. Bull. 1957, p. 108-128.

23 Wever, O. R., 1971. Some medical and sociopathological aspects of alcoholism in Aruba and its actual treatment. Proc. First Aruban Congr. Alcoholism, p. 135-187.

24 Wever, O. R., 1971. Brief report on alcoholism in Aruba, N.A. 17th Intern. Inst. on Alcoholism, West-Berlin; 11 pp. (not publ.).

25 Windt, H. L. de, 1971. Neuropsychiatric aspects of alcoholism in the Netherlands Antilles, especially referring to Aruba. Proc. First Aruban Congr. Alcoholism, p. 91-95. 